\title{
Using accounting information systems by operations managers in a project company
}

\author{
Henk J. M. van der Veeken* and Marc J. F. Wouters
}

This paper describes the results of a case study that investigated the use of accounting information by operations managers in a road building company. There was considerable preplanning before the execution of project activities, but task uncertainty during execution created the need to take corrective action. Information on prices and expected costs was crucial for preplanning purposes. During project execution higher-level managers depended upon accounting information about actual project costs to be able to focus on low performing projects. Lower-level managers observed work on-site and they used information about the prices of various resources. Learning over time happened on the basis of experimenting with practical ideas and building a repertoire of solutions that worked (or did not work). The study suggests that under high task uncertainty in projects, accounting information may not take on the role of a 'learning machine' to help managers decide on action, because managers may supply action-centred skills to manage cost. Action-centred cost management strategies for negotiation and improvisation are not informed by accounting information that supports analytical cost management strategies. The study also suggests that direct observation of processes is more informative compared to the representation of these processes through accounting information, if the complexity of these processes is limited (few different input and output resources).

(C) 2002 Elsevier Science Ltd. All rights reserved.

Key words: accounting information systems; operations management; building industry; project management; field research.

\footnotetext{
*Eindhoven University of Technology, School of Technology Management. E-mail: h.j.m.v.d.veeken@tm.tue.nl

Address for correspondence: Marc J. F. Wouters, School of Technology \& Management, Department of Finance and Accounting, University of Twente, P. O. Box 217, 7500 AE Enschede, The Netherlands. E-mail: m.j.f.wouters@sms.utwente.nl
} 


\section{Introduction}

In this paper we discuss the use of management accounting information by the operations management function in a project organization. Understanding how people outside the accounting function use accounting information in their work is important for management accountants. Understanding how operations managers do their work and how accounting fits in, may, however, not be easy. The study is partly motivated by notions of a 'gap between the traditional finance and operations perspectives' (Anonymous, 1996) which requires some 'rethinking about the expected usefulness of accounting information on the operational level' (Jönsson and Grönlund, 1988).

The use of accounting information has been studied in different ways. A major strand of literature has applied the contingency framework to the study of management accounting systems design and performance. These studies have found relationships between contextual variables (such as environmental uncertainty, span of control, task interdependence, and decentralization), the use of management accounting systems, and performance. See, for example, Gordon and Narayanan (1984), Chenhall and Morris (1986), Gul and Chia (1994), Mia and Chenhall (1994) and Chong (1996). These studies use questionnaire data from multiple firms and define the use of management accounting systems by certain information characteristics: breadth of scope, timeliness, levels of aggregation, and integrative nature. Swenson (1995), Foster and Gupta (1994) and Joseph et al. (1996) are examples of questionnaire studies that do not use the contingency framework and that provide insights into the use of accounting information for decision-making by operations management. There is another body of literature on the use of accounting information that is based on case studies. These studies generally are of an exploratory nature. See, for example, McKinnon and Bruns (1992), Scapens et al. (1996), Ahrens (1997), Jönsson and Grönlund (1988), Fry et al. (1995), Mouritsen and Bekke (1999) and Jazayeri and Hopper (1999).

The motivation for the present study is that there is not much knowledge of how operations managers, particularly at lower levels, use accounting information (Lukka, 1998). We do not understand very well the usefulness of accounting information on the operational level, and it is challenging to try to improve this (Jönsson and Grönlund, 1988). Operations managers have various concerns, such as quality, safety, efficiency, and completing activities on time. For daily, short-term activities, managers generally use non-financial operating data on units of output, units of input, scrap, quality, order quantities, inventory availability, etc. 'In 12 varied manufacturing companies, we found no instance of a key daily production indicator being a cost or other financial number' (McKinnon and Bruns, 1992, p. 42). However, accounting numbers become important as the horizon lengthens. The performance of managers is often measured in financial numbers and managers build a mental model of the financial implications of their actions that are guided by physical counts. Also, a longer horizon is sometimes needed, because of concern with costs rather than simply quantities (e.g. to control budgeted expenses, to identify problems and opportunities for improvement). The study of Jönsson and Grönlund (1988) is a good example here. They describe how operations managers in a production plant used cost data on tools over a longer period to detect problems and to monitor the results of experiments with new tools. 
Managers are often dissatisfied with the accounting information they receive (McKinnon and Bruns, 1992). The information is often too late, because accounting recognition and measurement criteria delay recognition of events until uncertainties have been resolved. Timely information is important because these managers have a desire to be continuously aware of the status of operations and the possible need for action or redirection of effort because of unexpected events or changes. Other sources provide information sooner. Secondly, reliability is often a problem. They need recently updated information, consistent definitions, and accurate registration. Thirdly, most problems with accounting data relevance centred around the suboptimal categorization of data or the failure of the system to present desired relationships in reports. Aggregation and allocation of costs tend to obscure details that are important to managers. Many of these technical points could probably be solved by better, faster, and more flexible information systems. But faster information per se is not a solution. There is a need to better understand how accounting information has its own function as part of a much larger set of information that managers use.

In this study we aim to provide a better understanding of the conditions that influence the usefulness of accounting information systems to operations managers. We study issues close to the shop-floor level of organizations, but not the link between accounting and (operations) strategy. We aim to study the role of accounting information from the perspective of operations managers: their work, how they obtain and use information, part of which is formal, written, or computer information (of which accounting information is again only a part). We want to understand if and how accounting information is integrated in the work of operations managers: does it help to understand the current situation, to prioritise issues, to direct their attention, to identify and analyse problems, to find and evaluate solutions? Or is accounting information placed outside the work of managers, because it is of no concern at all, or because it is something they only look at in the context of how their performance is being measured? We feel that this perspective is most directly related to the work of Jönsson $(1996,1998)$, Jönsson and Grönlund (1988) and McKinnon and Bruns (1992). We address four questions in the description and discussion of the case study findings:

1. What strategies do managers use to achieve planned financial project results?

2. In what way does accounting information contribute to these strategies?

3. Which factors explain the use of accounting information?

4. What are the implications for the design of accounting information systems?

We decided to do a single, in-depth, longitudinal case study because we wanted to obtain a rich description with unexpected examples of the use or non-use of accounting information. The study of McKinnon and Bruns (1992), for example, provided many insights by means of a study investigating each company for about 1 day. However, more in-depth results can only be obtained by spending much more time in a company, and over a longer period. In the terminology of Keating (1995), we aim to do a theory discovery case, which aims 'to map novel, dynamic, and/or complex phenomena ignored or inadequately explained by existing theories' (p. 69). 
The use of case studies in accounting research is discussed by, for example, Ferreira and Merchant (1992), Otley and Berry (1994), Brownell (1995) and Ryan et al. (1992).

Our findings confirm and expand the work of Jönsson and Grönlund (1988). Both higher and lower level managers in our study used detailed cost information when acquiring and planning the project to better understand expected project cost, to identify financial risk, and to plan the execution of the project such that cost targets can be met. We found that different management levels required different types of information to manage uncertainty during project execution. Output-oriented information on actual costs versus budgeted cost is crucial to higher-level managers for monitoring projects. Lower-level managers rely on observation of processes and use action-centred skills to manage the economic result of the project. Although these managers have to deal with much uncertainty during project execution, and accounting information may support managers in dealing with uncertainty by taking on the role of a 'learning machine' that helps to understand to financial consequences of actions for responding to uncertainty (Chapman, 1997), these managers do not look at accounting numbers to identify or solve problems. The study of Jönsson and Grönlund (1988) focuses on different ways of learning by higherlevel and lower-level managers, and they conclude that output-oriented accounting numbers do not support learning processes of lower-level managers (but such information is appropriate for higher-level managers). We suggest that the type of skills that managers use to manage costs during execution are relevant to explain the role of accounting information. Lower-level managers can directly observe project activities, and they use a few key metrics to monitor projects. When they identify problems, they apply action-centred skills for negotiation and improvisation, using their experience. These action-centred skills are not supported particularly well by accounting information. Accounting information enables more accurate planning (which is going to be changed and renegotiated later) and abstract analysis of data (while foremen are on-site and on the phone finding practical solutions), but this becomes less useful in the context of cost management strategies based on negotiation and improvisation for dealing with uncertainty in projects.

The paper is structured as follows. We discuss literature in Section 2 and introduce the research site in Section 3. Section 4 describes cost management of projects in the company studied. The discussion of the case study is in Section 5.

\section{Theory}

One of the difficult things in doing case study research is writing up the findings of rich case studies (Ahrens and Dent, 1998). Should we at this point in the beginning of the paper present hypotheses or a framework? We feel that the value of this exploratory research should lie in describing and theoretically explaining empirical findings that are surprising in the light of existing theory. We started the case study with a theoretical framework about the relationship between the complexity of decisions and the use of accounting information. However, during the case study we had to change our theoretical background, for several reasons. First, we discovered that measuring complexity was more difficult than we had anticipated. We used the GEMS model of Reason (1990) that distinguishes three levels of behaviour depending on the complexity of decisions: skill-based behaviour, rule-based behaviour, and 
knowledge-based behaviour. We were unable to explain decision behaviour of operations management by this model, because it was difficult to define measures for these levels. Secondly, and more importantly, as the case study progressed we felt that this initial theoretical model narrowed our view because things other than those anticipated turned out to be interesting in this company: the role of managers in the production process of accounting numbers, the tensions created by inaccuracies in the accounting numbers, the implementation of new accounting information systems, the difficulty of understanding how and why lower-level managers did not seem to use accounting information for cost control, and the lack of systematic analysis of completed projects for developing more accurate cost engineering norms. These were the issues that we encountered and that we decided to follow and focus our research on, because these could yield theoretically interesting insights. And so the framework presented in this section makes explicit our expectations that were not confirmed during the case study, which made these findings surprising. We guided the research in the direction of better understanding these surprises.

If activities have a low level of uncertainty and are well understood prior to performing them, they can be managed through preplanning (Galbraith, 1973). However, if they are poorly understood and during the actual execution of activities new knowledge is acquired, preplanning is not completely possible. During execution changes are made in planned resource allocations, schedules, working methods, priorities, etc. As the number of exceptions compared to plan increases, uncertainties have to be resolved during execution. As task uncertainty is greater, information processing during the task performance increases (Galbraith, 1973). Road building projects are managed through a combination of preplanning and adjustment during execution, because of task uncertainty. On-site conditions are sometimes different than planned for, mistakes are being made, and there are changes in project requirements. Cost management during execution is about dealing with uncertainties that materialize in that phase of the project, and information systems may be used to increase the information processing capabilities of the organization (Galbraith, 1973). Information systems may increase the capability to perform preplanning activities by providing more information about the task and during task execution such systems may support decision-making to respond to exceptions.

As there is more uncertainty the potential role for accounting information to help reduce uncertainty becomes more relevant (Chapman, 1997). When preplanning is less feasible and the number of exceptions increases, accounting information may take on the role of a learning machine. Accounting may be expected to be involved in helping to evaluate how alternative actions during task execution may achieve financial goals. It may help managers to understand their tasks more clearly before making their decisions and help them to take better decisions. The role of accounting information becomes one of 'providing information as to the financial impact of a range of operational decisions, so that if not the best, then at least better decisions about action can be made' (Chapman, 1997). However, as uncertainty increases, accounting information is probably not capable of fully capturing the operational considerations and these must somehow be involved in the decisionmaking process. The relationship between uncertainty and relevance of management accounting information has empirical support in the contingency literature (Gordon and Narayanan, 1984; Chenhall and Morris, 1986; Gul and Chia, 1994; Chong, 1996). 
Looking more specifically at accounting information for projects, cost reports should allow actual costs to be compared with the budgeted costs of the work done (Anthony and Govindarajan, 1998). In the calculation of the budgeted costs of the work done, uncertainties are incorporated. If work progresses faster than planned, more work is completed at a certain date than planned for, and the budgeted costs of the work completed at that point in time can be adjusted. If the work changes and other activities have been done compared to plan, the budgeted cost is also adjusted to reflect these changes and to allow a comparison with actual costs. Useful reports on costs and financial result provide information about the current status of the activities for which the manager is responsible and if problems are identified, the reports should help the manager to take action to resolve them (McKinnon and Bruns, 1992).

Analysing the costs of completed projects may help to build a better understanding of the relationships between actual costs and project contingencies. This would make perfect sense looking at this company's technology. Many projects are technically simple, however, some projects are technically more complex and are of a technicalprofessional technology (Macintosh, 1985; Withey et al., 1983). This means that task variety is high and task knowledge is analysable. In other words, there is substantial variety in the tasks performed, but the various problems can be handled by referring to a store of established knowledge and decision-making techniques. Macintosh (1985) suggests that information systems with large amounts of relatively unambiguous data can be used for such technologies. Managers can interact extensively with the database while massaging the information until the one best solution emerges. For building projects, this means that the company could analyse completed projects in order to enrich their database with information about actual costs of activities. They could analyse actual cost data in relation to project contingencies. They could build a database with more and more accurate and specific norms for project cost estimates. They could use that database to produce more accurate cost estimates for future projects, both initial estimates and estimates of the costs of project changes.

To summarize the argument thus far: because of the uncertainty of road building projects, we would expect the accounting information to be used to increase preplanning capabilities and project control during execution. Preplanning could be improved project control during execution. Preplanning could be improved by creating databases that allow more accurate cost estimation by taking into account information on relationships between actual costs and project circumstances. Project control could be improved by providing accurate information on actual costs, which can then be compared with budgeted costs for the work completed. As such, accounting information could take on the role of a 'learning machine' under conditions of uncertainty.

\section{Research site}

The case study is about one division of a large building company in the Netherlands. In 1999, total revenues of the company were about 1.243 billion Euros and profit was 34.3 million Euros; revenues of the division (also including some other activities that account for about $10 \%$ of revenues) were 476 million Euros. Within the division, 
we initially focused on two business units: road building and infrastructure (piping, cables, etc.). Later in the project we needed to spend more time with lower-level managers (the foremen) and we concentrated on the road building business unit.

We chose to do research at this building company for several reasons. The company is completely organized around projects. Such companies have received little attention in the literature on the use of accounting information. Second, the technology for some projects is complex, but it is still reasonably understandable for outsiders, and this condition makes it easier to understand the decision making of operations managers. Third, the company operates in a market with low profit margins of around 2-3 per cent of revenues. Cost control is very important and this makes it particularly interesting to study the role of accounting information for operations management in this company. Finally, the company is investing many millions of Euros to change its accounting information systems. They are implementing a new version of a company-wide enterprise resource planning (ERP) information system for accounting and planning (Baan4) and they are developing and implementing a system for on-site cost control (BPA). Thus, we could study why they changed their accounting systems and how new systems were being used. The company was willing to participate and wanted to receive feedback on their use of accounting information systems. Our initial contacts with the company were through the division controller.

The research project was a longitudinal case study that took place from December 1997 until September 1999. Data where gathered in interviews with operations managers and accountants on different levels in the organization (see Table 1). Five different levels of operations managers were interviewed: divisional managing director (MD), business unit $\mathrm{MD}$, assistant $\mathrm{MD}$, head project foremen, and site foremen. In total, we conducted 14 interviews with 13 individuals; $21.5 \mathrm{~h}$ in total. Eleven of these interviews were recorded and transcribed. The topic and aim of the interviews were introduced to the respondents by sending in advance a note explaining the aim and scope of the research together with a request to select as much information as possible (files, computer printouts, drawings, etc.) of an actual building project. We emphasized the importance of a concrete project with facts and figures to talk about. We followed an interview outline that addressed what financial project results they could influence and in what ways, to what extent they were really accountable and evaluated, what kinds of actions they took to influence results, how they judged situations to take actions, and what kinds of signals they used: formal information (financial-non financial), physical observation, or consultation?

In the interviews we discussed different reports that these managers received and other documents they used, and when possible we obtained sample documents (see Table 2). We also received documentation about the new information systems that the company was implementing (see Table 2). Other information came from observing head project foremen and site foremen in their daily work (see Tables 3 and 4). Furthermore, there were feedback presentations of the research findings and discussions with the company. As a result of one of these presentations for the divisional management in 1998, in which we suggested that foremen had many difficulties with the new information system, the company appointed a taskforce and hired more IT professionals for implementation support. We extended the research to include the findings of this taskforce and to gain a better understanding of implementation experiences and system use after an extended period. We structure 
Table 1

Interviews

\begin{tabular}{lcc}
\hline Function of interviewee & $\begin{array}{c}\text { Number of } \\
\text { interviews }\end{array}$ & $\begin{array}{c}\text { Duration of } \\
\text { interviews (hours) }\end{array}$ \\
\hline MD & 4 & 6 \\
(division and business units) & 3 & 4.5 \\
Controller or accountant & 1 & 1.5 \\
Information manager & 2 & 3 \\
Assistant MD & 1 & 2 \\
Head calculation office & 1 & 1.5 \\
Head project foreman & 2 & 3 \\
Site foreman & 14 & 21.5 \\
Total & & \\
\hline
\end{tabular}

Table 2

Sample documents

\begin{tabular}{ll}
\hline Reports & Information plans \\
\hline Quotations offered (list and summary report) & Company presentation about Baan4 \\
Orders received (per month and cumulative) & Manual BPA \\
Production realized (per week, cumulative) & Summary BPA \\
Billing (per month and cumulative) & Company article about BPA \\
Income statement of business unit (quarterly) & Company article about IT infrastructure \\
Financial information BU (monthly) & Report steering group (technical issues) \\
Liquidity planning & Report steering group (functionality) \\
Order portfolio & \\
Project results report & \\
Detailed project results report & \\
Project results mutation report & \\
\hline
\end{tabular}

Table 3

Observations

\begin{tabular}{lccc}
\hline Function & \# Different people & \# Different projects & Total duration (days) \\
\hline $\begin{array}{l}\text { Site foreman } \\
\text { Head project }\end{array}$ & 5 & 5 & 12 \\
foreman & 3 & (one project per foreman) & 3 \\
& & $\begin{array}{c}\text { (each responsible for } \\
\text { several projects) }\end{array}$ & 3 \\
\hline
\end{tabular}

the remaining part of the paper following the questions posed in Section 1 earlier: What strategies do managers use to achieve planned financial project results? In what way does accounting information contribute to these strategies? Which factors explain the use of accounting information? What are the implications for the design of accounting information systems?

\section{Cost management of projects}

In this section we describe cost management of projects, which is a combination of preplanning described in Sections 4.1 and 4.2 and managing uncertainty during 
Table 4

Results of observations of foreman

\begin{tabular}{lccc}
\hline Type of activity & $\#$ & $\begin{array}{c}\text { Use of technical } \\
\text { information }\end{array}$ & $\begin{array}{c}\text { Use of accounting } \\
\text { information }\end{array}$ \\
\hline Routine & $56(59 \%)$ & & \\
Non-routine & $46(41 \%)$ & & \\
\cline { 2 - 4 } & $112(100 \%)$ & 13 & 2 \\
Observation of work & 35 & 10 & -13 \\
Solving problems & 25 & 2 & - \\
Consultation & 33 & - & 15 \\
Administration & 14 & 40 & \\
Remaining & 5 & & \\
Total & 112 & & \\
\hline
\end{tabular}

execution as discussed in Section 4.3 (Galbraith, 1973). We discuss the roles of four different management levels within the business unit. The MD is responsible for the business unit's financial result. The business unit is a profit centre and the MD needs to contract and execute projects in a profitable way. The business unit has several local offices, and each local office has an accounting department, an assistant MD, and a profit and loss account. The assistant MD is the link between the MD and the lower-level managers. He works with the head project foremen and informs the MD on an exception basis. He chairs the weekly progress meetings with all head project foremen. Each head project foreman supervises and supports a number of site foremen; how many depends on the number and scale of the projects under construction. Sometimes a head project foreman is responsible for only one very large project. The site foreman supervises the workers on the site and is responsible for the execution of one medium-sized project or several small projects. He decides how the work is done and negotiates with the principal about changes during the project. In the case of far-reaching changes he consults with the head project foreman.

\subsection{Acquiring new projects}

The MD maintains commercial relations with customers and potential customers. Local and central governments are the main customers of the business unit. $\mathrm{He}$ examines tenders and works given out by contract, and he decides on which projects to bid. He negotiates prices with customers. He uses different kinds of information for bidding and negotiating: cost estimates, technical knowledge about risks, and market conditions.

The business unit's cost engineers in the calculation office produce cost estimates. A cost engineer uses the builder's specification that describes medium and largesized projects to estimate the cost. The cost engineer makes assumptions about how the project will be executed and he uses some standards for resources used and the resource prices for executing activities. The cost engineer checks the specification to judge the complexity of the work, and depending on this he will sometimes ask the head project foreman to observe the specific circumstances on site. Most of the time, however, calculation appears to be 'office-work' and rather 'theoretical', according to foremen. There are also many small projects, which are relatively simple and do not need advanced technical and financial calculations. Decisions for this kind of work 
are based on rules and standards like travel distance to work location, the amount of work, price per square metre paving, and so on. The head project foreman or the site foreman makes these decisions.

He uses his technical knowledge and experience to assess the risk involved in a project. He goes through the cost estimates for complex medium and large sized projects in detail. He looks at the estimates of costs and he looks at risks involved in the project and the reliability of the cost estimate. His price offer will depend on the project risk, because he needs to build in a buffer and he may adjust the way the project is executed. He gave the following example:

\begin{abstract}
If we have to lay a drainpipe with a diameter of 1.5 metres in the middle of the street, where there are all kinds of cables and pipes, then you have to work with system boxes, with shields on the sides. Those are activities that we don't come across very often and we don't have standards for that. Then there is the risk involved in making estimates. Whether you say, I will do 100 metres per day with one shift, consisting of a crane and that many people, because that is standard. Or you say I can do 50 metres in 1 day. But then you are 100 per cent wrong or 50 per cent too low. Those are the risky activities, activities with which we don't have sufficient experience. You have to make assumptions and discuss with the different people involved what the risks are and what the consequences of those risks are. I go through those kinds of activities.
\end{abstract}

He also uses information about competitors. It is a local market with small margins. He knows most of his competitors and how much work they have, because competitors in this business know who has tendered for specific projects and who actually won the bid for a project. The company has developed a simple information system (a spreadsheet) that keeps the score of all tenders of themselves and of their competitors in the region. They also have a rough insight into the capacity of competitors, so by simple bookkeeping of the regional markets they know how well loaded their competitors are. He tries to estimate the risk of not getting the job and uses this information in determining the profit margin. He also uses information about the workload of his own people and budget target realization of the business unit to date, to determine how eagerly he wants to get a new project.

In the end the MD makes a tradeoff between different aspects concerning the price decision. The main logic applied was that you can make a higher price when your business unit and your competitors are well supplied with work, the financial budget targets of the business unit will most likely be met, and you have an (little) advantage in technical know-how in comparison to the customer or competitor. It seems strange that they accept work while they are amply booked but it is a market with many subcontractors making it easy to apply flexible capacity measures. Apart from that, the tradeoff is not made explicitly in terms of calculations (except for the calculation of the builder's specification). It is a kind of estimation of the big picture with different aspects that is built up by the MD in consultation with all the parties involved that gives him a good or a bad feeling.

If the customer accepts the offer, the rough calculation is translated into a detailed budget for the project. Detailed activities are specified and costs for these activities are budgeted, and the timing of these activities is planned. The ways in which activities will be executed are also worked out in greater detail.

There is informal use of standards for the calculation of costs. People have a limited set of standards in their memory based on their average experience with comparable projects. Road construction standards concern labour and equipment hours for digging a metre of trench, laying a metre of drainpipe of a certain diameter 
range, and so on. Cost standards concern prices for a cubic metre of sand including transport, hourly rates for subcontracting labour or hiring a truck, and so on. The company maintains hardly any formalized database with standards. They argue that every project is so different that the use of 'standards from a book' would be risky. Thus most of the calculation knowledge is in the heads of the people working in the calculation office, but it is quite extensively shared among colleagues. This way of sharing and exchanging knowledge about standards during the process of calculation is their approach to making figures more accurate and more detailed.

\title{
4.2. Planning the execution of a project
}

The project is assigned to a head project foreman. Using the detailed budget it is possible for the foreman to judge the feasibility of the project budget in a more realistic way. The head of the calculation office said the following about this activity:

\begin{abstract}
At this stage the foreman and the engineer apply the art of sharp accounting: trying to stay below the level of calculated costs by shopping for lower prices and being smart at choosing the method of working.
\end{abstract}

If the head project foreman thinks the budget is not feasible, he will ask the calculation office to adjust specific norms and the total budget, because he is accountable for the ultimate financial result of the project. A head project foreman gave the following example:

\footnotetext{
In this calculation they used the same standard for digging a trench in the free field as in a busy shopping area. If you don't tell the calculation office that there is a difference, they assume you can do it in the same time. So I have negotiated some more time to get a more realistic budget for hours spent digging.
}

If the cost estimate based on the detailed calculation results in a serious difference with the earlier agreed price with the customer, the MD has to decide about adjusting the budgeted costs (making it tighter) or the design of the project (reducing costs). In the end the foreman will accept the project and budget. The common policy of the MD is not to inform the foreman about the expected profit margin of a project. So, the way a foreman judges the budget is mainly on execution terms, and especially the amount of man hours, since many of the projects contain mainly labour costs. The foreman makes an assessment of which elements of the budget are tight and which are easier, and the budget gives the foreman an impression of how knowledgeable the customer is regarding the technology and costs of road building.

The site foreman and the head project foreman plan the work before they start. Planning is about the following questions: How will I execute the project? What will I subcontract? Which, and how many, resources can I use, and how much progress do I have to make? They consider different ways of working, they identify risks and slack, and they make plans.

\footnotetext{
Can I realize it in a different way still meeting the specifications. You can of course be very ingenious. I can give you an example about the delivery of drainage pipes. When do I have these delivered at the site? Usually the supplier unloads the pipes at one location at the site before we have dug the trench and next day we drag the pipes along to the trench. You know the stories about just in time from industry? So I order the pipes and have them unloaded by the supplier in such a way that we have to move them only once, of course zero would be ideal, so right next to or in the trench. Ready in an instant. That requires organizing and thinking: When do I have which materials delivered?
} 
Foremen also use outsourcing to manage costs. They outsource work to specialized subcontractors to eliminate risks (fixed prices) and to reduce costs of regular work (by trying to put pressure on them). Foremen know the subcontractors for road construction in their region and they have a pretty good idea how much work these subcontractors have and what their prices are. There are a lot of small-sized subcontractors that work very flexibly and depend on a large company like the one we investigated here. These small subcontractors can often work cheaper because of their low overhead. Foremen use their knowledge of the regional subcontracting market to shop around for the best prices and flexible capacity in case of potential risks.

Foremen translate their plan into guidelines for how much progress they have to make and how many resources they can use to achieve the planned financial result. They use informal knowledge about the prices of resources, such as the cost of one person per hour, the cost of a dump truck per day, and so on.

\begin{abstract}
Look, the project budget control figures are exact figures, but actually you know how the project is going by your observations at the building place. If after a few weeks you see the project and find that they have made 140 metres including some special jobs, you know they are ahead of schedule and they will meet the budget target.

If they obtained such a project then you have to do the job. You have to realize the project within the budget that is at your disposal. That is your job, that is the assignment, and you get down to it. So you know what the target is. You will do all that is possible to realize the project within the budget. You look at the project budget: We have so many hours to spend, what's our capacity? What's important for us is what we can spend per metre, per day, per hour, those kinds of things. Those are the standards I have to use. Let's say they expect that we can realize 2 or 3 metres per hour, or that many tons, cubic metres, or whatever. That's what you use.

The standard prices, that's what it's all about. So, how long can I take for a job? Suppose I have to dig a trench, what will I deploy? I bring into action two cranes with four men. That's 500 guilders an hour times $8 \mathrm{~h}$ is 4000 guilders per day. If the standard price is 40 guilders for 1 metre of trench, it means that I have to dig 100 metres per day with my group to balance things financially. Then I cover my costs. When I can do it faster, I know I am making a profit.
\end{abstract}

The way foremen translate financial targets starts with a budget breakdown by period and physical standards built up on the basis of past experience and shared experience among colleagues. If there are unique elements in the builder's specification, the foremen make rough physical estimates. The more experience a foreman has the more he can rely on 'comparable unique elements' from projects in the past-if he can remember. Solutions for problems may be found through analysing financial data, but observations and other kinds of data such as construction drawings may be more informative, because observations and drawings fit with their way of learning which is strongly based on visual pattern recognition and action experience. It is learning by doing and experimenting, rather than abstracting.

\title{
4.3. Cost management during execution
}

The company cannot rely only on the preplanning of activities discussed earlier. There is uncertainty during project execution, and higher-level managers (MD and assistant MD) and lower-level managers (head project foreman and site foremen) have various roles in managing these uncertainties in an attempt to achieve the project's planned financial result. 
A characteristic of road building activities is that there are many uncertainties and work changes during execution. Flexibility and improvisation are required. Uncertainties arise because on-site conditions are different from those planned, either because there was no on-site inspection when preparing the work, or because conditions could not be inspected beforehand (for example, where it is below the ground). There are also uncertainties because of mistakes and things going wrong (machines breaking down, suppliers and subcontractors being late, etc.). Another source of uncertainty is that the principal sometimes changes the specifications. Because of uncertainties, many projects are built differently from the plans that were produced before the project started. As a result, costs are different from those forecasted and, depending on the kind of arrangements made with principals, revenues may also differ. A questionnaire study done in 1997 by the division information manager indicated that about 40 per cent of initial specifications changed during execution.

Cost management by higher-level managers. The MD monitors the execution of projects and intervenes when he receives signals that the financial result of a project may become significantly different from what he expects based on how he negotiated the project. For example, he calls in the head project foreman to discuss solutions for improving the project's financial result (and to put more pressure on the foreman), and he sometimes assigns another foreman to the project. Accounting information is a main source of information for monitoring projects, because the MD cannot observe all the projects and cannot talk directly to all head project foremen. He wants to know whether the financial result of the project is actually developing as he expected when he accepted the project. He receives a weekly report of 'project results' with total costs and revenues for each project (one line per project). He also receives a quarterly income statement for his Business Unit. Both reports are output from the company's accounting information system. Every week he makes a selection of projects from the 'project results'. For instance, he does not look at small negative results, he does not investigate projects that have been discussed intensively before and that are now improving, he does not investigate projects that have an unrealistic budget and for which it is already accepted that it will have a negative result. The selected projects (one or two of a total of about 20 projects) are reviewed with the assistant MD in weekly progress meetings.

When the MD and the assistant MD look into a project in detail, they do not have detailed project cost information from the central accounting system. That system only contains total costs and total revenues per project and is used for reporting to headquarter. The MD's previous experience using the more detailed accounting figures from the existing central accounting system were so bad that he decided not to use it for his own control purposes. He explained as follows:

If you ask me: Can you use it for project control? I will answer that the output is some kind of bookkeeping record; for me this thing is a monster. It is so user unfriendly that I decided to stop using it 5 years ago. It worked in theory but if you make some registration or interpretation mistakes, and who doesn't, it's a hell of a job to trace them. Then the whole table was covered with lists and reports.

I simply turned off the switch of the system. That's unpleasant of course when the external auditor is asking for information, because it is the only thing for him to hold on to. An auditor wants to know to what extent I have control of my organization. The only thing the good man can handle is cost accounting and I offer him a cowboy story. He then tells 
me: How can that be? I had to explain to him twice; the third time he didn't ask me any more.... But every time he makes a remark about that in the accounting letter to the division management.

Why does the accounting system not provide an up-do-date analysis of total costs and revenues of a project at a certain point in time? It is difficult to record costs and work progress completely and to match these to an identical point in time. The accounting department determines project costs on the basis of invoices and forms that are provided by the site foremen concerning hours worked by company workers and external costs for subcontracting, rent, and materials. Invoices for materials often arrive together with on-site deliveries. The foreman signs the invoices and sends these to the accounting department. Invoices from subcontractors and from companies that rent out equipment usually come later, because the number of hours worked and rented is only known at the end of the week. The foreman signs the forms from the subcontractor so they can prepare their invoice, and the foreman completes forms about the costs incurred and sends these to the accounting department that creates a cost accrual. The foremen need to perform these administrative activities because there is no accountant on site. The difficulty is, that both costs and work-inprogress can either be running ahead or running behind, for example: material has been delivered, but has not yet been used; subcontractors have done the work, but have not yet sent a bill or another document; production is not recorded completely, but costs are already recorded. Of course, when a project is completed the actual costs are sorted out and the final invoices to the principal are negotiated and sent, and then the financial project result is known. Also, every quarter they have to really sort out the actual costs and actual production for their major projects, when they have to externally report financial results. But meanwhile, the registration of both costs and production is generally not up to date and there is inaccurate matching.

So when the MD and the assistant MD want to look into a project in detail, or when cost accounting mistakes become apparent, it takes much effort to produce the right numbers. The assistant MD starts digging in the manual project file and administration, chasing the responsible foreman about administrative setbacks, checking numbers, correcting data, recording costs, etc. All the administration of a project is filed in a project binder. It contains the builder's specifications, drawings, contracts, hour notes, changes of specifications, manual drafts of details of the work and the first calculated project budget. The assistant MD prepares a detailed analysis of the financial project result and an estimate of the remaining costs and revenues, and the room for negotiations with the principal. He estimates margin at the end of the project. When we see these managers around a table full of paper, reviewing invoices, work reports, etc., this is not because they are using the data to manage their work. They are part of the administrative procedures to input and to correct the numbers. The MD considered the present situation with the accounting information to be inadequate for control 'because that's like walking on quicksand'. The company decided to make significant investments in information technology to improve the available information on actual costs and revenues on projects.

Cost management by lower-level managers. Foremen are actively managing the costs and financial result of their projects during execution. Here we focus on small or medium-size projects that have no on-site cost accountant and that are managed by one foreman. The financial result is important to foremen and they are cost 
conscious. However, they manage costs without using much financial information. Foremen plan the usage of equipment, workers, subcontractors, and materials. They are busy arranging things by phone, talking with the workers, the principals, and worried people living in the neighbourhood of the building site. The main focus of control is on avoiding delay of the project and making a good road according to technical specifications. Their most important source of information is drawings and the builder's specifications. The use of financial information is very rare during execution; sometimes they use prices such as the hourly charge for a truck to be hired or a cubic metre of white sand. These figures are in their memory. Decisions made by the foremen during execution are not preplanned most of the time, but are often based on improvisation and craftiness. We will discuss how they manage costs and the financial result through planning the work, observing the actual work, improvising for uncertainties and work changes, and negotiating about surplus work. They learn from successful solutions used to manage costs in earlier projects.

We base our description on interviews and on observations of the activities of eight foremen during 15 days in total, carried out by a research assistant, see Table 3 . We described 112 activities with action triggers, purpose of the activities, information used, and time spent for the activity, see Table 4 . Many activities (41\%) were ad hoc, unplanned, corrective activities driven by all kinds of unexpected events, for example: phone calls with suppliers that have delivered too late, looking for a worker who did not show up, talking with a principal who does not agree with the way the work has been completed, etc. The explicit use of accounting information for cost management purposes occurred only two times in 112 activities. In both cases this was in response to an unexpected event. In one case a truck with sand that did not arrive because it had not been planned, so the foreman went shopping for the cheapest alternative supplier. The second activity concerned a well that was filled up with garbage and needed to be cleaned. This was not budgeted because the well was clean at the start of the project. The foreman had to calculate a cost for cleaning and dumping the garbage and bargain with the principal who was paying for the extra costs. Apart from these two instances, most of the information used was purely technical, namely drawings and builder's specifications.

Foremen observe the work during execution and relate that back to their planning. In the planning phase they have informally formulated certain operational milestones they can observe on site. These milestones concern the required progress, which can often be measured in metres or square metres, and the allowable resources that are used. Actual progress and resources utilized can be observed, and when they verify that they are making the required progress and are not using more resources then planned, they know total costs should be within the budget. They do not use accounting information about the actual costs of the project. From their daily involvement with the project, they already have a notion of how the financial result of the project is developing; accounting information gives no new information. When the accounting numbers are surprising, it is usually because they are incorrect.

Usually if strange things are in it, which you cannot explain at first sight, then it always concerns an administrative step. Somewhere it is going wrong. When something goes wrong, then I immediately say, yes we had bad weather last week for two and a half days. That I can tell right away. But when the weather has been great and it is in the red nevertheless, then it usually is an administrative mistake. The cause can be the administration or the foreman. 
Question: So actually one can say that you check predominantly for administrative mistakes, because other differences you already know?

Foreman: Yes. See, you already feel outside if there is money earned or there is a loss. Yes, you say it will be about this. It can be a thousand above it or below it. It's a feeling you just have. Not the first week, but after a few weeks into the project.

These observations inform foremen that if things are less efficient than planned (less progress or having to utilize more resources than planned), they need to take action. Actual conditions may be different than expected during the planning phase, weather has an impact on the processes, and mistakes may be made. Action may also be initiated by required changes in the specifications. Dealing with uncertainty is the essence of cost management during execution and foremen do this in several ways and they use various types of information, which we will discuss in the remaining part of this section.

Foremen have to improvise in the way the work is executed to manage uncertainties and changes during execution. Road building work offers many possibilities to change the order of activities, as compared to other building projects, because all activities are done on the surface. They can start working on another part of the road. In other building projects, there are many more sequential dependencies between activities (for example: you have to add a new floor to a building before you can start doing plumbing, wiring, etc. on that floor). In recent years the mobile phone has become a very frequently used tool for improvising.

Foremen use informal knowledge about prices to make decisions about the actions they take to solve problems. Many decisions taken by head project foremen and site foremen concern the management of resources, such as subcontracting of activities, renting of equipment, planning a crew of workers on the site. They negotiate directly with several suppliers and consequently have knowledge about current prices of resources. This knowledge, however, is less actual for materials that are purchased by the corporate purchasing department, such as asphalt and concrete, and for equipment rented from other divisions within the company.

Another way in which foremen manage the financial results of projects is through negotiations with the principal. For example, a foreman explained about a project that he had finished, and that in the beginning looked as if it was going to be unprofitable:

The trick: the principal was willing to sign a surplus work form so I could compensate some earlier setbacks. There was a lot of unexpected rubble in the dug up sand, so we had to dump it instead of reusing it. I told the clerk of works of the principal that it would cost 90 guilders a cubic metre extra to dump it but that I would make a deal with him to dump it at a small farmer for half the price. He agreed not knowing that I had to pay the farmer only a few cents. The farmer could use the rubble as foundation for building a road on his land.

Technical inexperience or carelessness of the customer can be used in price negotiations or later on during the building process. A foreman stated the following:

\footnotetext{
Normally the builder's specification does not specify in detail how to make the drainage for a highway. So we make it in a standard accepted way. When however the principal tells us during the work that he wants to have it made differently we know that the technique costs about 1000 guilders more. At that moment I start reading the builder's specification literally and if it is not specified he has to pay surplus work. That's no problem; it's a matter of how literally you read the builder's specification. All kinds of discussions can arise about one single word that is interpreted in different ways. But you have to be careful that you don't ruin the entrepreneurial atmosphere because at that moment the principal is going to split hairs and then you really have a problem. That's the game we play every day.
} 
It is a subtle game to play. According to the assistant MD:

Sometimes a principal has a sharp budget target himself and you help him in realizing it. Later on he has more budget margin and he will make you a deal. A builder's life is a question of give and take.

Foremen use solutions that worked before. They learn to manage the costs and the financial results of projects from experience about how similar problems had been solved before. There is learning through recognition of similarities with specific projects from the past. The MD of a local office put it as follows:

This project threatened to go into the red from the beginning. I had a bad feeling about that so I looked at the builder's specification and work preparation again together with the head project foreman and we concluded that we were faced with comparable problems as a project 2 years ago at a different location. I immediately phoned the foreman that was in charge at that time and of course he remembered that dog project. He has advised the foreman in charge and we finished the project with reasonable figures.

Oral information exchange in meetings and consultations is an important source of concrete information. Managers exchange informal, oral information during the weekly meetings about project progress and during many unplanned interactions, making a lot of use of their mobile phones to communicate. The mobile phone makes it easier to get information from the work preparation office, to make and change arrangements with suppliers and subcontractors, to negotiate with the principal, and to consult higher-level management on how to act in a particular situation. It is a tool that is entirely consistent with negotiation and improvisation as strategies for dealing with uncertainty during execution. It provides an important compensation mechanism in case of missing formal information, is easy to use, and enhances the richness of information exchanged in direct interaction. Oral communication is also used to obtain approval for proposed corrective actions and securing the commitment of higher-level managers. It permits a sharing of risk and responsibility from the moment the foreman has consulted his superior.

Summarizing, this section answers the first question formulated in Section 1 regarding the strategies that managers use to achieve planned financial results. Accounting is an important source of information in the preplanning stage, both for higher-level and lower-level managers. Cost estimations are used to negotiate prices and detailed cost budgets are used to plan the execution of a project. Higherlevel managers monitor projects during execution on the basis of information on actual and allowable costs. Lower-level managers observe the progress of the work, and if the work had been executed as specified. These managers do not depend on cost accounting information to monitor projects and to solve problems, in contrast to higher-level managers. They resolve uncertainties created by mistakes, changes, unexpected conditions, etc. which emerge during the work on the basis of their experience and some rough information about prices of various resources. Unexpected conditions and changed specifications require improvisation and create the need for additional negotiations with the customer. Foremen are in daily contact with the customer's representative and they build a personal relationship. It is give/take, also going from one project to another. The foreman can use unexpected cost savings to execute the project in a less costly way, and/or negotiate for the customer to pay for unbudgeted work. Uncertainties create the opportunity for additional cost management strategies that replace detailed calculations and detailed monitoring as cost management tools. 


\section{Discussion}

This paper discusses cost management in projects that are characterized by uncertainty that materializes during execution. In Section 4 we described what strategies managers used to achieve planned financial project results. We will summarize in what way accounting information contributes to these strategies, which was the second central question formulated earlier in Section 1.

It was no surprise that higher-level managers used accounting information for cost management as an output measure. They wanted up-to-date information on actual and allowable costs to see which projects needed their attention. They were responsible for many projects and could not observe these on the site. To understand the cause of problems and to take action, higher-level managers would look into the accounting data for a project in more detail, talk with the foreman, and take action to improve the financial result if needed. At first, however, they would ask the foreman to check that data are complete and up-to-date. When, after correcting the data, there was still an unfavourable financial situation they discussed the problems with the foreman and helped in finding practical solutions at the level at which the responsible foreman is not authorized. For example, the MD replaced people on the project and brought in more experience, or he negotiated at a higher management level with the principal. Higher-level managers could help in finding practical solutions as they have considerable experience due to the company's tradition of promoting from within, and they were often capable of judging and consulting in relation to the everyday problems of foremen.

Lower-level managers were also interested in the economic results of their projects. They would carefully review project budgets before execution, negotiate for higher budgets with higher-level managers, plan the execution to achieve the agreed result by selecting appropriate working methods. Prices of resources and the project cost budget were the most important financial information they used. They would determine their expected cost on the basis of the prices of resources selected and they compared this with the allowable cost in the budget. They would also derive milestones that could be verified by observation for the projects, such as: required progress of the work and allowable resources utilized on site. These operational measures were used to monitor project execution.

There was one very important type of accounting information that was not used by lower-level managers: actual project costs in comparison with budgeted cost of the work completed (Anthony and Govindarajan, 1998). Providing lower-level managers with this type of information was one of the objectives of the new building place automation (BPA) information system that the company had implemented. The BPA system started about 3 years ago and was first implemented as a pilot, but meanwhile had been expanded to about 200 users (all the business unit's site foremen and head project foremen). The MD talked about how the new version of the BPA system was supposed to work once it was fully developed:

\footnotetext{
The most valuable thing is that monitoring a project costs much less time and can be done with less delay, because you follow it more tightly. You give the foreman a modern tool, with which they can do their administrative tasks in a minimum of time. You give the foreman the advantage that things can all be done quickly, if they know how the system works. A second advantage is that we draw together all kinds of information that makes it possible for us to follow a project every minute-much faster than before. In the old situation you were 1 month behind. Now it's possible to monitor every day, if you want.
} 
The problem is that it is not yet integrated. That's the disadvantage. Everything has to be repeated manually.

They earn a lot of administrative time because they only have to click with the mouse, word-processing is at a minimum. At any moment they can push on the button and they have the most recent financial state of all their projects.

The BPA system was designed very much in line with results reported by McKinnon and Bruns (1992) who found that 'useful reports relate directly to actionable managerial tasks of managers receiving them. They contain and highlight information that is necessary for specific operating decisions or for monitoring key success factors. They eliminate uncertainties about status and key results for which the manager is responsible' (p. 132). The foremen could, to a large extent, determine the structure of the information (level of detail of reporting different types of costs and level of detail of reporting costs of activities). They entered the data into the system, so they would understand the reliability and completeness of the information. They could experiment with different ways of presenting the reports. They could input the actual project progress and the system could then determine the allowable costs. ${ }^{1}$ Furthermore, the design of the BPA system was consistent with the findings of Jönsson and Grönlund (1988). The system is a good illustration of the way in which information systems for different management levels can be integrated, even though these management levels may need different types of information for cost management purposes (Jönsson and Grönlund, 1988). The new information systems potentially offered lower-level managers information that was tailored to their local needs, while at the same time it was integrated with a managementreporting module of an ERP system for higher-level managers. The new information system was designed to facilitate learning at lower levels, while providing outputoriented information to higher levels. Yet, to both our and the company's surprise, not many foreman used the new tool to analyse costs.

This brings us to the third central question: Which factors explain the use of accounting information? We suggest later that two factors explain much of what took place in this case study and these factors are likely to have more general implications: the informational value of accounting information and the dominance of actioncentred skills.

\subsection{Informational value}

Our study suggests that informational value is an explanatory factor for the use of accounting information by lower level managers: in other words, how much accounting information contributes compared to other types of information to answer basic questions that managers pose: Am I on target? If not, what is the cause? What action can I take? Accounting information may or may not be the most appropriate kind of information to answer such questions. The amount of

\footnotetext{
${ }^{1}$ The BPA system contained a translation of the builder's specifications into a budget. The budget for a project was broken up into three levels. First, the work was broken up into builder's specification items, which were specified by the principal. Second, these items were broken up into cost control items which contained a specific technical part of the project with all the budgeted costs for making this part. For instance, a cost control item for a roadblock needed for security during the project contains transportation costs, hiring costs of material and equipment, and working hours to install. Third, the cost control items are broken up into more detailed sub-posts. Costs (resources used) are recorded at the level of cost control items.
} 
information processed is a function of the diversity of the output, the number of different input resources utilized, and the level of goal difficulty (Galbraith, 1973). When output diversity is low and the number of different input resources is also low, managers may be able to translate their financial targets into a limited number of operational targets, and observations of the operations and some key non-financial figures may provide a good indication of whether financial targets are being met. For example, meeting the material budget for bricks is easier to monitor by counting the pallets of bricks used and comparing them to the square metres paved, than retrieving the usage figures from the accounting information system. The work is then sufficiently transparent to conclude from observations whether financial targets are being met. When corrective actions are needed, the limited number of input resources involved means that a basic understanding of their prices can be sufficient to provide an indication of the financial impact of alternative courses of action.

Accounting information may be particularly informative for cost control during execution when output and input diversity are high (Galbraith, 1973). In that case, non-financial information and informal cues are more likely to be ambiguous about achieving financial targets. Some activities have been completed using more resources than planned, others have used less, and it is unclear whether financial cost targets are still being met. On the basis of non-financial information and prices of input resources only, it is probably also unclear which corrective action is most appropriate: some actions require more resources of one kind, other actions require resources of the other kind, and it may be unclear which action contributes most to achieving the required financial target. Accounting information about the profitability of projects, products, channels, and customers expresses the net effect of all kinds of disturbances and actions that take place. In situations of many different inputs and outputs, it becomes unclear whether financial targets are being met, and which actions are best to take. But in other settings such as in our case study company, the answers to such questions are pretty clear.

\subsection{Action-centred skills}

We suggest that the usefulness of accounting information for operations management depends on the extent to which the information is consistent with the type of actions that managers take to manage costs. When, during execution, unexpected, unplanned conditions arise or specifications change, managers must respond. This often requires action-centred skills for motivating people, negotiating with suppliers, colleagues, and customers, improvising and practical problem solving, managing relationships, gathering and distributing oral information, etc. These are actioncentred skills (Zuboff, 1988). Action-centred skills are based on concrete cues, but the inference process of what to do based on those cues remains relatively implicit. Knowledge is embedded in practical action and people cannot explain how they exactly do what they do (like typing, playing the piano, skilled carpentering, sports, leading a meeting). Action-centred skills require tacit knowledge, and they are learned through experience and by talking with other people about concrete things. Accounting information such as provided by the BPA system is typically not very supportive of action-centred skills. Accounting information provides abstract cues about the current situation. It assumes a more deliberate, analytical, cognitive process to understand the current situation and to take action. It supports analytical skills to think deliberately and analytically about questions for cost management, such as: Are 
financial targets met? What are the causes of disturbances? Which actions are needed to meet financial targets? In answering such question, accounting information would take on the role of a 'learning machine' to help managers achieve organizational objectives under uncertainty (Chapman, 1997). However, the action-centred skills that are used to actually manage uncertainty and to reach goals may not be supported particularly well with accounting information on actual costs and budgeted costs as provided by sophisticated information systems.

We suggest that our discussion of the role of action-centred skills extends the conclusions by Jönsson and Grönlund (1988). They discuss that local information needed for managing costs is likely to be different from central information needs, because local managers use different ways of learning. Jönsson and Grönlund (1988) suggest that information systems should facilitate learning at lower levels, while being integrated with output-oriented information systems for higher levels. Higherlevel managers are more distant from operational processes and will use outputdata comparing plans against budgets, and this will also lead to learning based on conceptual models. Output-based information systems that are suitable for higherlevel managers are of little help for lower-level managers. Those systems provide signals that something is wrong, but do not provide causal information for taking corrective action. Lower-level operations managers need a few operating statistics to determine if things are out of control. Learning is more experiential and based on direct observation of processes. Local managers need to be able to formulate these operating statistics and change them over time. They focus on one problem at a time, take action, determine whether costs have improved, and then refocus on another problem (Jönsson and Grönlund, 1988, p. 524). Lower-level managers have an image of causal relations, and they try to complement that image with relevant operating statistics. Therefore, information systems must be flexible so that managers can retrieve the key indicators and diagrams they feel they need for the problem they are currently focusing on. They need to be able to connect the measures with other sources of information, because they need to be able to 'see with your own eyes and talk to the people closest to the events' (Jönsson and Grönlund, 1988, p. 524).

Our study also found that different managerial levels require different information for monitoring, because lower-level managers can observe processes and have a few operational measures derived from their planning. However, we found remarkably similar ways of learning from history. Both higher-level and lower-level managers learned from past projects. They talked about projects and they remembered and exchanged concrete experiences about how they solved problems. Managers made frequent use of their experience with previous projects, based on specific examples of what worked and what did not work. We did not find that higher managers learned from history by looking at output measures, distant from the operational processes. The company had not developed extensive databases with information that would enable more accurate cost calculations. Initially accurate cost calculations for projects that are going to be changed considerably as time passes, were not considered to be particularly useful in this company. Instead, action-centred skills were important to achieve profitable projects. Recognizing the role of action-centred skills in projectcost control and discussing the implications for the use of accounting information is a contribution of the present study.

We conclude that the usefulness of accounting information for operations management depends on the informational value of such information compared to 
non-financial information, and on how consistent such information is with the skills that are used to manage costs. This conclusion brings us to the fourth question formulated in Section 1: What are the implications for the design of accounting information systems? We will suggest that these systems should better support managers in dealing with uncertainty, they should support learning and action-centred skills, and they should facilitate communication between the different managerial levels that have their own information needs. Although these suggestions may not be exclusively supported by the empirical evidence gathered in this study, these implications are derived from the case study findings.

\subsection{Need to support uncertainty}

Plans and budgets are often prepared as if they are certain, even when it is quite likely that uncertainties will materialize during the execution of the activities. By definition, uncertainties cannot be foreseen and fully dealt with during planning. But during the planning stage it may be possible to identify some future risks and possible changes to the plan. The information system could specify not only the plan, but also point to elements of the plan that are uncertain, describe reasons for the potential uncertainty, and suggest solutions.

Plans and budgets in the case study company did not contain much explicit knowledge about uncertainties and risks that might already be identified during the negotiation and work preparation phase. Information systems could incorporate risk management during all stages in the lifecycle of projects. Starting at the calculation phase, the estimated risks can be part of negotiations with the principal. At the work preparation phase, the second stage of the project lifecycle, risks could be anticipated by developing a flexible resource plan and budget, based on best practice scenarios. Such plans would make foremen aware of risks at the start of the execution phase, beyond the risks that foremen are able to assess based on their experience. To draw a simple analogy: suppose you travel and someone else has arranged your trip and planned a connecting flight, but the planner knows that it is quite possible that you will miss your connection. You would like to know this in advance and you would like to know what the next flight is, if that happens. If you see this in advance, you might also decide to plan your trip differently, because taking an alternative airport might be practical for you in a way that the planner cannot anticipate. This example illustrates that some uncertainties can be identified and that it is useful that planners explicitly communicate these uncertainties to the people at the operational level. Such information is diverse and not very structured. Information systems need to support sharing such information about uncertainties. And this takes us to the next step after making uncertainties explicit: information systems also need to help managers find solutions for resolving uncertainties.

\subsection{Need to support learning and action-centred skills}

People learn action-centred cost management skills through experience, and this learning is based on observing concrete examples, experimenting with practical ideas, and building a repertoire of solutions that worked (or did not). Learning is limited to an individual's personal experience and that of a few colleagues with whom information can be exchanged. Information systems for cost management should facilitate such learning processes and allow managers to benefit from a larger experience base. 
Information systems could collect information on problems that occurred in projects and the conditions under which they happened. Such information might help managers to anticipate problems even though they have not encountered the problems before. What are the risky parts of projects from a technical point of view? What on-site conditions need special attention? The information should allow managers to check whether certain risky situations apply to their projects. They do this already using their own experience, so adding information based on other people's experiences would be consistent with this way of working. Information systems could also provide suggestions about how to solve such problems. The system could collect information on practical solutions for dealing with uncertainty and the results of earlier uses of these solutions and the conditions under which they were tried. Such information could be used in the planning and execution phases of a project. The challenge is to find ways of selecting solutions that are relevant to a specific situation. A database could at first identify past projects at a general level by size of the project, way of tendering, technical type, etc. and proceed with more specific information, such as the name of the executing foreman, technical specifications of unique parts (builder's specification, drawings, digital pictures, etc.), problems that were solved with practical hints (do's and don'ts), technical and financial consequences of potential solutions.

\subsection{Support different managerial levels}

Accounting information is less useful for performance evaluation under uncertainty, when managers have to deal with exceptions during execution-despite preplanning efforts (Chapman, 1997). It is more important that local managers can respond to uncertainties and changes, than that they can execute an initial plan against standard costs. This raises the question of how higher-level managers can use accounting information systems to understand and evaluate the way in which local managers have dealt with the uncertainties? The 'problems and solutions database' might be included in performance evaluation. When projects encounter a high level of uncertainty, but much of which has been identified in the information system and potential solutions are available, the lower-level managers might be expected to anticipate and react quickly using tested solutions. However, when uncertainties are encountered which have not been experienced before (at least, no information about them is stored), and when problems needed to be solved that have not been solved before, the task of the foreman is much more difficult. The point is that systematic information on problems, conditions under which they occurred, solutions, and conditions under which they worked (and did not work) may not only support managers in dealing with uncertainty, but may also provide some basis for judging what performance has been achieved and whether managers could reasonably have been expected to anticipate and solve these problems.

One limitation of this study is that, as with many case studies, more information could have been gathered that would allow further testing and refining of the proposed explanations. High on the 'wish list' would be hard data on information system use by individual foremen and data on their characteristics such as age, experience, and education. A few foremen may be using the accounting information in ways we do not really understand. Some may rely not only on action-centred skills, but also use accounting information in an analytic way. If so, why and how do they do this? Furthermore, it would have been helpful to compare our findings with 
situations of the very large and complex projects with on-site cost accountants and more diverse resource inputs. We would also liked to have had more observations of foremen, in particular during the weekly project meetings with higher-level managers.

Overall we feel that the case study method was worthwhile, because only in this way was it possible to describe and make sense of the managers' use of accounting information in relation to the cost management strategies they applied, which were based on preplanning, monitoring a few operational measures, observation, negotiation and improvisation. In the literature there is very little empirical description of how managers close to operational processes try to influence financial results and how they make use of accounting information and other information to support their cost management strategies. The experience from conducting this case study suggests that the design of accounting information systems should be guided by an in-depth understanding of the strategies that operations managers (information system users) follow to achieve their financial goals, and a thorough comprehension of their information use in these management process (formal versus informal information, financial versus non-financial). There is a danger in developing more advanced accounting information systems based only on accountants' or information systems experts' perceptions of how to manage operations.

We suggest two routes for future research aimed at better understanding how operations managers can be supported by accounting information. First, it is relevant to study the introduction and functioning of innovative accounting information systems in real companies. What expectations did the various users and the system designers have about the accounting information? What information do these systems actually generate, how is it used and valued by managers, how does the information impact the performance of managers? What were the planned and the actual implementation processes? In-depth research about the use of management accounting information could look at different types of information sources and information exchange, such as formal and informal, financial and non-financial, oral information versus printed or on-screen information, information that is readily available versus information that takes more effort to retrieve, etc. Such research could investigate the various kinds of actions that managers take to achieve economic results and the ways in which these actions interact with information use. Second, there is a more fundamental question about accounting information for operational managers and the strategies operational managers use for achieving financial goals. It would be relevant to use decision theory and other theories from cognitive psychology to better understand, for example, when financial or nonfinancial information is more informative (Luft and Shields, 2000). Further theory and more empirical results, from case studies and experiments, are required to better understand how managers use different types of information to support cost management strategies in operations.

\section{Acknowledgements}

We thank Sten Jönsson, Thomas Ahrens, Frank Selto, Jacques Theeuwes, Bob Scapens, and the two reviewers for their many valuable comments and suggestions on earlier versions of this paper. 


\section{References}

Ahrens, T., 1997. Talking accounting: an ethnography of management knowledge in British and German brewers, Accounting, Organizations and Society, 22, 617-637.

Ahrens, T. and Dent, J. F., 1998. Accounting and organizations: realizing the richness of field research, Journal of Management Accounting Research, 10, 1-39.

Anonymous, 1996. Role of IE continues to evolve, IEE Solutions, 28 (12), 18-23.

Anthony, R. and Govindarajan, V., 1998. Management Control Systems, McGraw-Hill, Irwin.

Brownell, P., 1995. Research Methods in Management Accounting, Coopers \& Lybrand Accounting Research Methodology Monograph No. 2 Coopers \& Lybrand and Accounting Association of Australia and New Zealand.

Chapman, C. S., 1997. Reflections on a contingent view of accounting, Accounting, Organizations and Society, 22 (2), 189-205.

Chenhall, R. H. and Morris, D., 1986. The impact of structure, environment, and interdependence on the perceived usefulness of management accounting systems, The Accounting Review, 61 (1), 16-35.

Chong, V. K., 1996. Management accounting systems, task uncertainty and managerial performance: a research note, Accounting, Organizations and Society, 21 (5), 415-421.

Ferreira, L. D. and Merchant, K. A., 1992. Field research in management accounting and control: a review and evaluation, Accounting, Auditing \& Accountability Journal, 5 (4), 3-34.

Foster, G. and Gupta, M., 1994. Marketing, cost management and management accounting, Journal of Management Accounting Research, (6), 43-77.

Fry, T., Steele, D. C. and Saladin, B. A., 1995. The role of management accounting in the development of a manufacturing strategy, International Journal of Operations and Production Management, 15 (12), 21-31.

Galbraith, J., 1973. Designing Complex Organizations, Addison-Wesley Publishing Company.

Gordon, L. A. and Narayanan, V. K., 1984. Management accounting systems, perceived environmental uncertainty and organization structure: an empirical investigation, Accounting, Organizations and Society, 9 (1), 33-47.

Gul, F. A. and Chia, Y. M., 1994. The effects of management accounting systems, perceived environmental uncertainty and decentralization on managerial performance: a test of three-way interaction, Accounting, Organizations and Society, 19 (4/5), 413-426.

Jazayeri, M. and Hopper, T., 1999. Management accounting within world class manufacturing: a case study, Management Accounting Research, 10, 263-301.

Jönsson, S., 1996. Accounting for Improvement, Elsevier Science.

Jönsson, S., 1998. Relate management accounting research to managerial work, Accounting, Organizations and Society, 23 (4), 411-434.

Jönsson, S. and Grönlund, A., 1988. Life with a sub-contractor: new technology and management accounting, Accounting, Organizations and Society, 13 (5), 512-532.

Joseph, N., Turley, S., Burns, J., Lewis, L., Scapens, R. and Southworth, A., 1996. External financial reporting and management information: a survey of U.K. management accountants, Management Accounting Research, 7, 73-93.

Keating, P. J., 1995. A framework of classifying and evaluating the theoretical contributions of case research in management accounting, Journal of Management Accounting Research, 7, 66-86.

Luft, J. and Shields, M. D., 2000. The Effects of Financial and Nonfinancial Performance Measures on Judgment and Decision Performance. Working Paper.

Lukka, K., 1998. Total accounting in action: reflections on Sten Jönsson's Accounting for Improvement, Accounting, Organizations and Society, 23 (3), 333-342.

Macintosh, N. B., 1985. The Social Software of Accounting and Information Systems, John Wiley.

McKinnon, S. M. and Bruns, W. J. Jr, 1992. The Information Mosaic, Harvard Business School Press. 
Mia, L. and Chenhall, R. H., 1994. The usefulness of management accounting systems, functional differentiation and managerial effectiveness, Accounting, Organizations and Society, 19 (1), 1-13.

Mouritsen, J. and Bekke, A., 1999. A space for time: accounting and time based management in a high technology company, Management Accounting Research, 10, 159-180.

Otley, D. T. and Berry, A. J., 1994. Case study research in management accounting and control, Management Accounting Research, 5, 45-65.

Reason, J., 1990. Human Error, Cambridge University Press.

Ryan, B., Scapens, R. W. and Theobald, M., 1992. Research Method and Methodology in Finance and Accounting, Academic Press.

Scapens, R. W., Turley, S., Burns, J., Joseph, N., Lewis, L. and Southworth, A., 1996. External Reporting and Management Decisions, London, CIMA Publications.

Swenson, D., 1995. The benefits of activity-based cost management to the manufacturing industry, Journal of Management Accounting Research, 7, 167-177.

Withey, M., Daft, R. L. and Cooper, W. H., 1983. Measures of Perrow's work unit technology: an empirical assessment and a new scale, Academy of Management Journal, 26 (1), 45-63.

Zuboff, S., 1988. In the Age of the Smart Machine, New York, Basic Books. 